\title{
As formas elementares da vida eletrônica: a agência social de elementos químicos metálicos usados na fabricação de smartphones.
}

\section{Guilherme Oliveira de Souza*; Paulo V. M. Calixto*; Pedro G. S. L. Paulino*; Stefano Schiavetto Amancio; Pedro P. Ferreira.}

\section{Resumo}

Esta pesquisa faz parte de uma investigação coletiva sobre a agência social de elementos químicos metálicos utilizados na produção de smartphones. Nesta pesquisa, em especifico, investigamos bibliograficamente a agência social dos elementos cobre (29-Cu), ouro (79-Au) e chumbo (Pb-82).

\section{Palavras-chave:}

cobre, ouro, chumbo.

\section{Introdução}

Esta pesquisa foi parte de um esforço mais amplo de investigação sobre a agência social dos elementos químicos, i.e., sobre as articulacões entre: propriedades atribuídas a elementos químicos; e características do grupo social que pratica essa atribuição (cf. Ferreira 2019). Em particular, esta pesquisa investigou a agência social de 3 elementos metálicos usados na fabricação de smartphones: cobre (29-Cu); ouro (79-Au); e chumbo (82$\mathrm{Pb}$ ). Pesquisamos diferentes aspectos (históricos, culturais, políticos, econômicos, jurídicos, ambientais, fisiológicos, físico-químicos e tecnológicos) da existência desses elementos, ligados à vida humana em sociedade, e em especial à vida eletrônica mediada por smartphones.

\section{Resultados e Discussão}

Cobre, ouro e chumbo participam, há milênios, da história da humanidade (cf. Venetsky 1981), compondo, junto com a prata, o mercúrio, o ferro e o estanho, os sete metais alquímicos originais (cf. Eliade 1979). Se a ancestralidade do cobre, do ouro e do chumbo é normalmente atribuída à sua disponibilidade ambiental (cf. Krebs 2006), tudo indica que a persistência de sua relevância na sociedade capitalista global contemporânea está ligada à sua centralidade na fabricação de circuitos eletrônicos.

O cobre, metal com a segunda maior condutividade elétrica da tabela periódica, está presente principalmente nas placas de circuito impresso $(\mathrm{PCl})$ e nos fios elétricos, e corresponde a aproximadamente $13 \%$ do peso de um smartphone. Estima-se que mais de $35 \%$ do consumo mundial atual de cobre é reciclado. O ouro está presente principalmente nos fios de ligação entre o microprocessador e a $\mathrm{PCl}$, correspondendo a

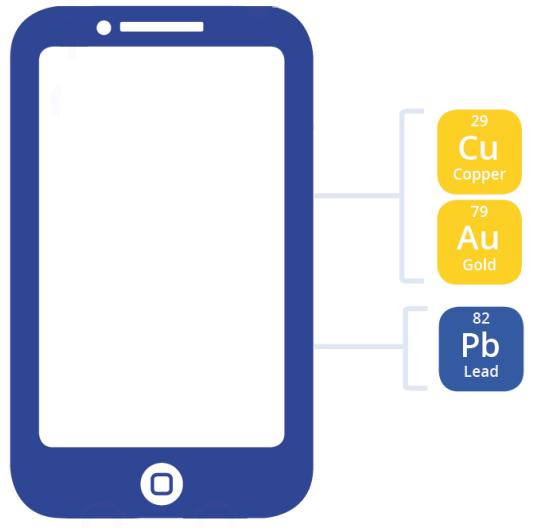

aproximadamente $0,14 \%$ do peso de um smartphone. A resistência do ouro à oxidação é um dos seus principais diferenciais na composição de ligações elétricas confiáveis e duráveis. O chumbo está presente nas soldas, na forma de uma liga com estanho, e corresponde a aproximadamente $0,3 \%$ do peso de um smartphone. Apesar de inofensivo para o usuário do aparelho, o chumbo tem efeitos socioambientais nocivos em grandes quantidades, e vem sendo substituído por outros elementos em ligas para solda (cf. ICA 2017; Fiorucci etal. 2012; Mukoyama 2010; Yu etal. 2010).

\section{Conclusão}

Como argumentou Émile Durkheim (1996), as formas como as sociedades, ao longo da história, encontram para classificar e representar as agências de seus ambientes, estão intimamente ligadas às formas como elas classificam e representam a si mesmas. Não poderiam as características socialmente valorizadas do cobre, do ouro e do chumbo na fabricação de eletrônicos (condutividade elétrica, ductibilidade, resistência à oxidação etc.) nos ensinarem algo sobre os valores de nossa própria vida social contemporânea, cada vez mais eletronicamente mediada?

\section{Agradecimentos}

Agradecemos ao CNPq (PIBIC-EM) pelo apoio

financeiro.

BRUNNING, Andy. 2014. The chemical elements of a smartphone. Compound interest. Acessível em: https://www.compoundchem.com/2014/02/19/thechemical-elements-of-a-smartphone/.

DURKHEIM, Émile. 1996. As formas elementares da vida religiosa. São Paulo: Martins Fontes.[1912]

ELIADE, Mircea. 1979. Ferreiros e alquimistas. Rio de Janeiro: Zahar.

FERREIRA, Pedro P. 2019. Sociologia elementar: a agência social dos elementos químicos. Acessível em: https://sociologiaelementar.wordpress.com/.

FIORUCCI, Antonio R.; BENEDETTI FILHO, Edemar; OLIVEIRA, Noé de. 2012. Os alótropos do estanho: ocorrência do estanho 'alfa' e as novas soldas sem chumbo usadas em eletrônicos. Química Nova na Escola 34(3):124-30.

ICA. 2017. Copper recycling. International Copper Association. New York: Copper Alliance.

KREBS, Robert E. 2006. The history and use of our Earth's chemical elements: a reference guide. Westport: Greenwood Press.

MUKOYAMA, Koichiro. 2010. Gold bonding wire. In: Christopher Corti; Richard Holliday (eds.). Gold: science and applications. Boca Raton: CRC Press, pp. 287-94

NRC. 2017. Copper facts. Natural Resources Canada: Minerals and Metals Facts. Acessível em: https://www.nrcan.gc.ca/our-naturalresources/minerals-mining/minerals-metals-facts/copper-facts/20506

VENETSKY, S. 1981. Tales about metals. Moscow: MIR Publishers.

YU, Jinglei; WILLIAMS, Eric; JU, Meiting. 2010. Analysis of material and energy consumption of mobile phones in China. Energy Policy 38:4135-41. 